The $B D J$ News section accepts items that include general news, latest research and diary events that interest our readers. Press releases or articles may be edited, and should include a colour photograph if possible. Please direct your correspondence to the News Editor, Arveen Bajaj at the $B D J$, The Macmillan Building, 4 Crinan Street, London N19XW or by email to bdj@bda.org

\section{GDC gives last CPD warning}

Dentists in the last year of their first five-year continuing professional development (CPD) cycle who have failed to make any annual declarations are being warned by the General Dental Council (GDC) that their registration is at risk.

The GDC has written to alert these dentists, and to give them an opportunity to make a declaration of the CPD hours they have completed since their cycle started in 2002. Dentists who cannot show they have met the CPD requirements by the end of 2006 will be removed from the GDC register.

The GDC's compulsory CPD scheme was introduced in January 2002 to encourage dentists to update and develop their skills and knowledge for the benefit of patients and the profession. Under the scheme, all dentists must complete 250 hours of CPD every five years. At least 75 of these hours must be spent on verifiable CPD, and documentary evidence of these activities must be kept.

GDC Chief Executive and Registrar, Duncan Rudkin commented, "All dentists need to fill in a CPD declaration form each year to make sure they are on track with the Council's CPD requirements. Completing the form is a legal requirement. We found that approximately 400 of the 11,000 dentists now in the last year of their first CPD cycle had not made any annual declarations at all. By not complying with the requirements of the scheme, these dentists stand to lose their registration."

General Dental Council

\section{Dental charity celebrates 10th anniversary}

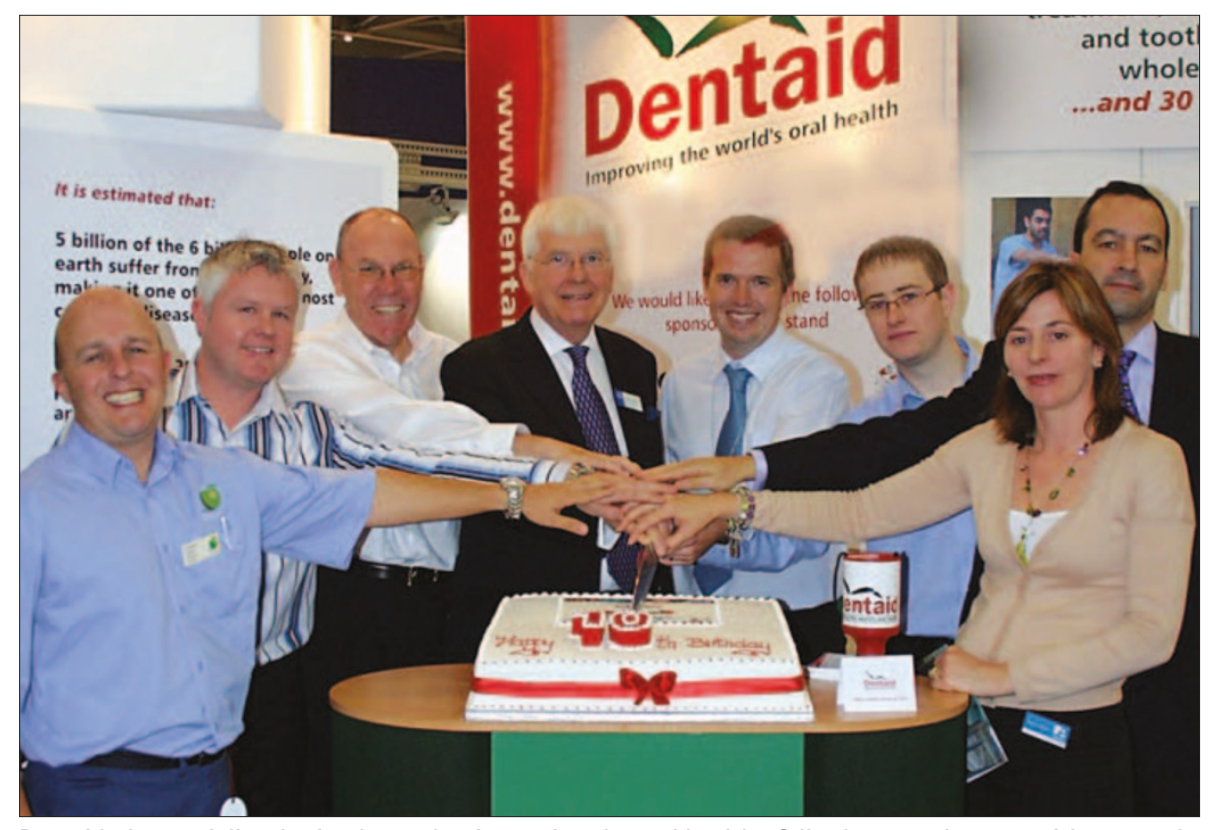

Dentaid, the specialist charity devoted to improving the oral health of disadvantaged communities around the world, celebrated its tenth anniversary this October and chose to share the occasion with many of its supporters at the recent BDTA Dental Showcase.

During the cake cutting ceremony Chief Executive Luke Wordley thanked all those who had supported the charity over the years. The charity was started in 1996 with one person, a garage and a $£ 10,000$ grant and has grown over the years to become a leading oral health charity, having helped over 150 charitable projects overseas to improve oral health for the needy communities they serve.

As Dentaid continues to grow it has started to broaden its activities in the developing world, embarking on major new initiatives in oral health promotion, training, advocacy and campaigning, as well as expanding its traditional work of supplying dental equipment and resources to regional clinics and running school based oral health programmes.

Dafydd Pierce of the fundraising team at Dentaid said, "Thank you to everyone who has supported Dentaid over the years. Since we started we estimate we have helped relieve the dental pain and improve the lives of over a million people in 50 countries. However, studies have shown that in some low income countries, $95 \%$ of children aged 11-14 with tooth decay remain untreated and it is estimated that still only $20 \%$ of the world's population have access to fluoride in any form. We still have a lot of work ahead of us and donations and fundraising are essential to maintain and expand this life saving work and we couldn't do it without your continued and generous support." Pictured above, Dentaid and some of its corporate supporters celebrating the charity's 10th birthday at the BDTA Dental Showcase.

Luke Wordley, Dentaid's Chief Executive, added, "In many parts of the world there is little or no access to a trained dental professional. This can mean enduring the pain and suffering of toothache, abscesses and other complications day in, day out, with no hope of relief. Fluoride toothpaste, toothbrushes and oral health education are beyond the means of most people. Many do not even understand the causes of their pain and oral health problems. Our goal is that, with the help of our generous supporters, individuals, corporates and volunteers, in another ten years we will have helped 100 million people." 


\section{Dental infection link to diabetes during pregnancy}

Nearly one out of two women with gestational diabetes also have periodontal disease, according to a study released last month by Tulane University researchers. In contrast, just over one in ten pregnant women without gestational diabetes have periodontal disease. The study, available in the October issue of the American Journal of Obstetrics and Gynecology, claims to be the first to demonstrate a link between poor oral health and diabetes during pregnancy.

Gestational diabetes is an inability to process dietary sugars normally during pregnancy and puts women and their babies at increased risk of injury and illness. The team of researchers analysed health data from 256 pregnant women who participated in the National Health and Nutrition Examination Study III. Based on their analysis, Tulane obstetrician Gabriella Pridjian, Tulane epidemiologists Xiong $\mathrm{Xu}$ and Pierre Buekens and Louisiana State University dental health researcher Sotirios Vastardis recommend that dental care

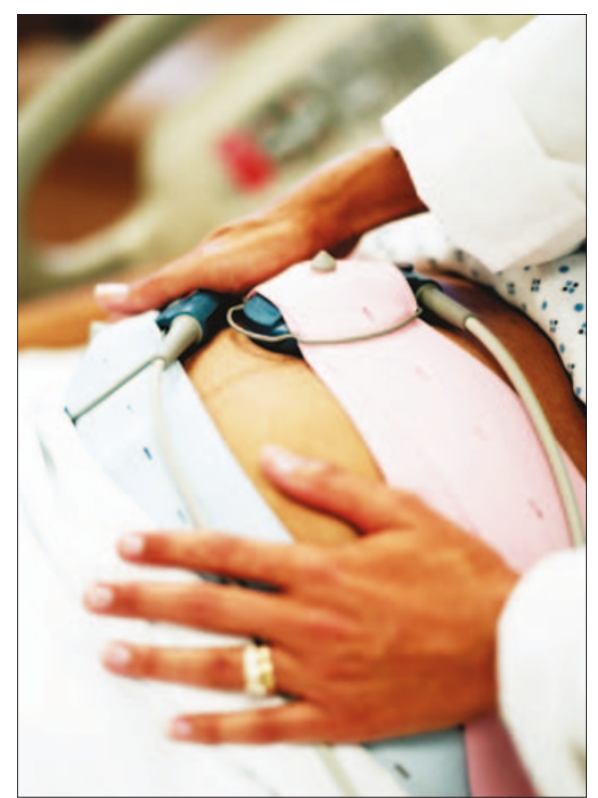

during pregnancy should be considered as a way to help prevent gestational diabetes.

\section{New guidelines launched}

The Faculty of General Dental Practice (UK) (FGDP(UK), has announced the publication of Standards in Dentistry (SiD), a comprehensive package of standards and guidelines for all members of the dental team.

SiD brings together all existing standards and guidelines in oral healthcare, encompassing those common to both primary and secondary care. A widespread consultation exercise during its development ensured that SiD underwent rigorous review, with contributions from numerous bodies including the GDC, the Department of Health, the BDA and specialist societies.

The package has an innovative format that combines a printed manual with an online publication, allowing for frequent updates to the information. The manual builds on the approach used in the FGDP(UK)'s first and seminal publication, SAMS, and includes clinical outcomes of care and treatment across 17 clinical areas.

\section{Focus on alcohol abuse}

A major new research programme to tackle alcohol problems was launched recently at a national conference hosted by St George's, University of London. A new £3.2 million implementation national research programme of alcohol screening and brief intervention, funded by the Department of Health, will identify the best method of helping people with alcohol problems attending primary care,

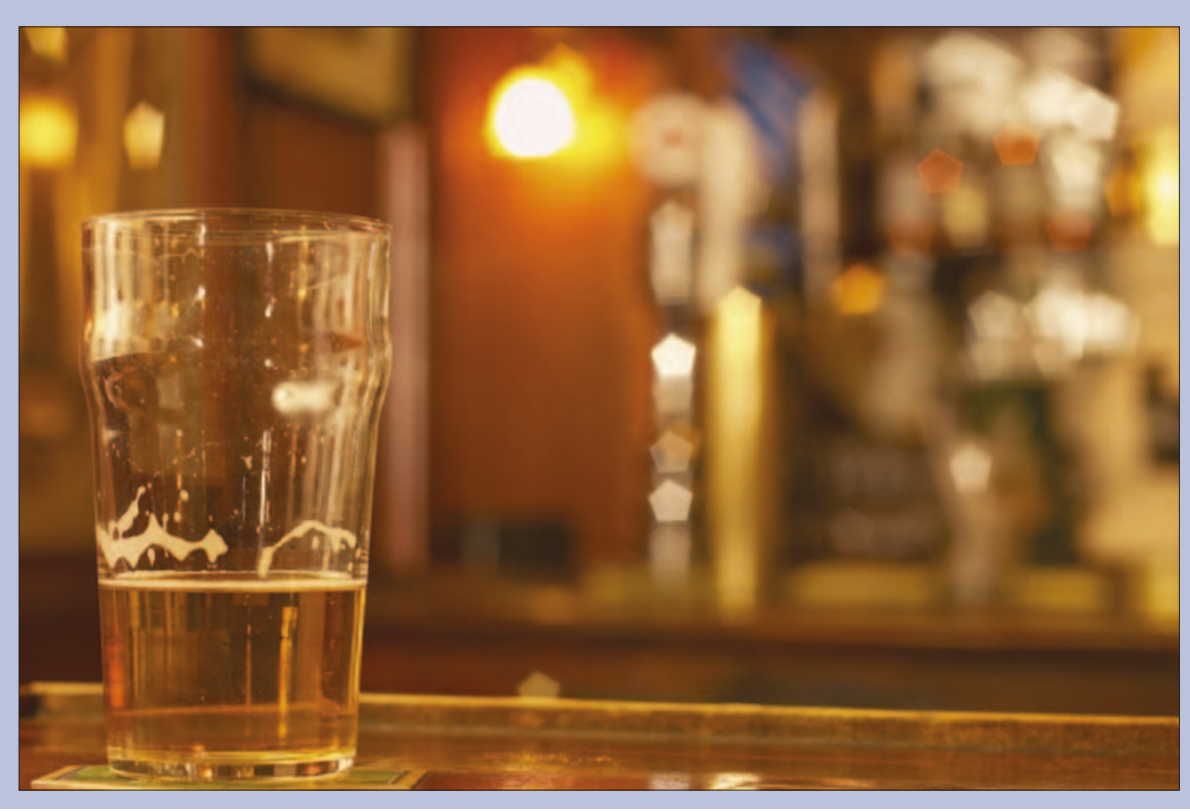

accident and emergency departments, and criminal justice agencies in England.

Alcohol misuse and dependence affect 8.2 million adults in England leading to an estimated cost to society of £20 billion per annum. Alcoholic liver disease is at an all time high level, and alcohol is now the third leading cause of ill health after tobacco and high blood pressure. This research programme, known as the

"Alcohol Screening and Brief Intervention Trailblazers", aims to find the best method to identify people who are drinking in a harmful way at an early stage, and to provide advice and support to prevent alcohol related harm.

As well as evaluating the impact on alcohol consumption and health, the research will assess the cost savings to health and social care services of screening and brief alcohol intervention. Chief investigator, Professor Colin Drummond of St George's, University of London said, "This will be the largest alcohol treatment research project ever conducted in the UK. This programme aims to find the best method of helping those people whose lives and health are affected by alcohol. Together with our partners, Universities of Newcastle, York, Imperial College and the national non-statutory agency on alcohol misuse Alcohol Concern, we aim to be able to recommend to the government the most cost effective method of helping people who are drinking in a harmful way, in health and criminal justice settings."

See paper on page 581; "A comparison of alcohol and drug use among dental undergraduates and a group of non-medical, professional undergraduates".

See paper on page 587; "Facing up to binge drinking: reducing binge drinking in adolescent males". 


\section{Oral lesions and paediatric HIV}

Oral lesions are commonly associated with paediatric HIV, according to a study that looks into the effects of the disease on children. The study, which appeared in a recent issue of General Dentistry, the Academy of General Dentistry's journal, found type, severity and progression are all factors that differ, depending on the age at which one contracts the disease.

Across the globe, the presence of HIV is wide-spread. At the end of 2004, the United Nations HIV/AIDS programme estimated that 2.5 million children under the age of 15 were affected worldwide.

"Children do not demonstrate HIVspecific symptoms as adults do," says
Kishore Shetty, lead author of the study. "Their bodies will most likely display an infection or weakness instead of common HIV signs."

He adds that the place where this most often occurs is in the mouth, commonly through candidiasis or 'thrush, a fungal yeast infection, salivary gland enlargement, herpes simplex virus, inflammation of the gingiva and canker sores. "Orofacial manifestations of HIV are common in paediatric HIV infection," Dr Shetty says. "It is important to be aware of these signs, as they may serve as both a marker of infection and predictor of HIV progressing to AIDS."

\section{Mouth cancer awareness week}

This week is Mouth Cancer Awareness Week, run by the Mouth Cancer Foundation with the aim of raising awareness of the cancer, which causes more deaths per number of cases than breast cancer, cervical cancer or melanomas. To highlight its importance, the Mouth Cancer Foundation has organised the Mouth Cancer Walk, a sponsored 10K walk in Hyde Park on 19 November.

According to founder of the organisation Dr Vinod K Joshi, in the UK there has been a 19 per cent increase in cases from 3,673 in 1995 to 4,405 in 2002. Due to late detection the mortality rate from mouth cancer is just over 50 per cent. Despite treatment, there were 1,703 deaths in 2002 - approximately one every five hours. Dr Joshi explains that the chances of survival are greatly improved if the cancer is detected early and treated rapidly.

"Mouth cancer patients suffer greatly owing to disabilities such as facial deformity, loss of teeth and damage to the tongue and throat, with consequent difficulty in talking and eating in public places. 13,000 people are currently living in the shadow of this debilitating disease. Yet they do not receive the attention and support that other cancer sufferers do," he says.

According to the Foundation, dental health professionals can warn patients of the dangers of tobacco use and alcohol abuse, alert Asian patients to the dangers of paan and gutka chewing, can screen patients for mouth cancers and be involved in efforts to increase awareness of mouth cancers and the need for support for head and neck cancer patients.

Leaflets and posters on lowering the risk of mouth cancer are available free of charge from the Mouth Cancer Foundation and can be used as discussion tools during consultations or displayed in the waiting room. Wristbands and t-shirts are available too.

For more information visit http www. mouthcancerfoundation.org.

\section{Mouth Cancer Awareness Week 12 - 18 NOVEMBER 2006}

\section{BDA ballot}

The BDA is negotiating a new contract and associated pay scale with NHS Employers for dentists working in salaried primary dental care in England. The aim is that this will be implemented from April 2007. When the contract has been agreed by both parties, the BDA will ballot members and non members. It is anticipated that a ballot will take place in January 2007. To ensure that the BDA has accurate and up to date contact details, please email the following information to SPDCSBallot@bda.org:

1. Full name

2. GDC number

3. Member - Yes/No

4. Full postal address

5. Employing Trust

6. Grade

7. Phone number and fax

8. Email address. 


\section{DIARY}

November

British Academy of Cosmetic Dentistry's (BACD) 2nd Annual Conference

Venue: Britannia International Hotel,

London

Date: 16-17-18 November 2006

Email:info@bacd.com

www.bacd.com

The 2006 ADF Conference and

Trade Exhibition

Date: 21-25 November 2006

Venue: Palais des Congrès de Paris, France

Email:adf@adf.asso.fr

www.adfcongres.com

\section{Moving to Private Practice - practical considerations \\ Date: 24 November 2006 \\ Venue: Macrobert Arts Centre, \\ Stirling, Scotland \\ www.bda-events.org}

Health Protection Agency: Laser and IPL Sources Safety Training for Medical and Cosmetic Applications

Venue: HPA Radiation Protection Division, Leeds

Date: 28 November 2006

Telephone: 01132679041

www.hpa.org.uk

December

LDC officials' day 2006

Date: 1 December 2006

Venue: Tower Hotel, London

www.bda-events.org

January

1st International meeting on

Cold Laser Therapy in Dentistry

Date: 18 January 2007

Venue: New Orleans, USA

Tel/Fax: (888) 891-6485

5th Annual North American Orthodontic Conference for Full Face Orthodontic

Study Group

Date: 19-21 January 2007

Venue: New Orleans, USA

Tel/Fax: (888) 891-6485

\section{Periodontal disease and ischaemic stroke}

People missing some or all of their teeth or who have significant loss of bone and tissue surrounding their teeth may be at an increased risk for having a stroke, according to a new study that appeared in the October issue of the Journal of Periodontology (JOP).

Researchers from Boston University investigated the relationship between periodontal disease and history of stroke in patients 60 years of age and older by examining the data of the Third National Health and Nutrition Examination Survey (NHANES III).

The researchers found that that patients of 60 years of age and older who were edentulous, partially edentulous and/or had significant clinical attachment loss were more likely to have a history of stroke compared to dentate adults without significant clinical attachment loss.

Dr Martha E. Nunn, Goldman School of Dental Medicine, Boston University said, "Based on the results of this study, it is unclear whether periodontal disease is an independent risk factor for stroke or simply a risk marker that reflects negative effects of risk factors common to both periodontal disease and stroke." Age, tobacco use, hypertension, diabetes, serum glucose, C-Reactive protein (CRP) and alcohol intake were also included as additional risk factors in this study. These confounders are independent risk factors for cardiovascular disease and if lef untreated, periodontitis has been shown to have harmful effects on the control of diabetes and serum glucose levels, and to increase CRP levels.

Evidence continues to accumulate associating severe periodontitis with an increased risk of forming atherosclerotic plaques, which are responsible for myocardial infarction and ischaemic stroke. According to past JOP studies, this relationship could be due to elevated CRP levels in patients with chronic periodontal disease.

\section{Reforms not improving access to NHS dentistry}

Reforms to NHS dentistry have not improved access for patients, according to a survey of dentists by the British Dental Association (BDA). Fifty-five per cent of those surveyed said that the new contractual arrangements did not allow them to see more patients. A further 23 per cent said they were seeing about the same number, and those surveyed were not optimistic that they'd be able to see more patients in the future. Sixty-two per cent said they did not expect to be able to see more patients in the future, with a further 20 per cent unsure about how many patients they would be able to see.

The BDA Omnibus Survey also reported significant concerns about problems with the substantial number of contracts signed in dispute. Almost half of those who participated in the survey had signed their contract in dispute. Of those contracts signed in dispute, more than half were yet to be resolved. Nine of the 47 per cent who reported their dispute had been resolved were unhappy with how that resolution had been achieved and said they might leave the NHS as a result.

Additionally, the survey found practitioners had reduced the amount of NHS work they did as a result of the new contract and that further decreases in the amount of NHS work were also likely in the future. Just over 30 per cent of respondents performed 95 per cent or more of their work on the NHS prior to the implementation of the new contract. That figure had reduced to 25 per cent of those surveyed in the months after implementation. Furthermore, only 15 per cent believed they would be carrying out that much NHS work by the middle of 2007, and only nine per cent thought they would be by mid-2009.

Lester Ellman, Chair of the BDA's General Dental Practice Committee, said, "These figures paint a grim picture for the future of NHS dentistry. The new contract is failing to achieve its aim of making access to NHS dentistry easier for patients. The survey reflects anxiety and frustration among the dental profession and highlights the need for an urgent and thorough review of the impact that the government's reforms have had."

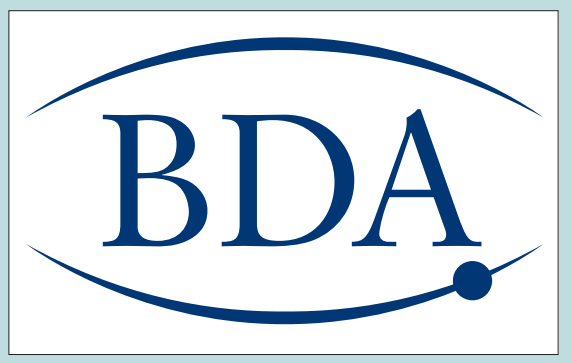




\section{Opportunity to work with charity}

A UK dental charity has announced an opportunity for members of the profession and public to join its Board of Trustees. The British Dental Health Foundation is a dynamic and proactive organisation, dedicated to promoting the benefits of good oral health to the public.

Established for more than 30 years, the Foundation operates a free national Dental Helpline service (0845 063 1188) as well as organising National Smile Month and Mouth Cancer Awareness Week.

The Foundation requires enthusiastic, committed individuals to govern the organisation and assist in the development of strategic objectives. Dr Nigel Carter, chief executive of the Foundation commented, "We are fully committed to improving oral health, both in this country and abroad. This is a fantastic and unique opportunity for someone with the necessary drive and passion to help us make a difference."

Trustees are required to meet four times per year and at strategic planning sessions, as necessary. For further information, please contact the British Dental Health Foundation, Smile House, 2 East Union Street, Rugby, Warwickshire, CV22 6AJ.

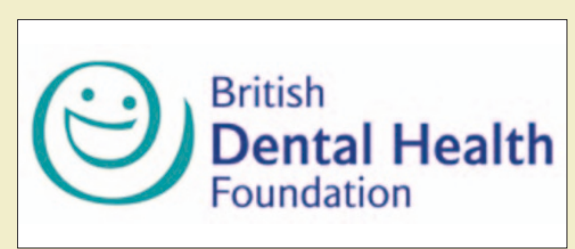

\section{Victims of violence to receive counselling}

Victims of violence are to be given advice on alcohol and aggression while receiving their medical treatment thanks to a pioneering new scheme.

Nurses based at Glasgow's Dental Hospital are being trained to give victims of facial injury - such as knife wounds - a brief talk on the consequences of alcohol and violence at two Scots hospitals, the Southern General and Monklands District Hospital.

The 12 month trial is a joint initiative with Glasgow University's Dental School alcohol research group - this is a multi-disciplinary group, chaired by Professor Ashraf Ayoub, consisting of surgeons, psychologists, psychiatrists, statisticians and nurses - and the Violence Reduction Unit.

In the UK, almost a quarter of all facial injuries are associated with interpersonal violence, while half of these are associated with alcohol.

Mr David Koppel, a Consultant Craniofacial surgeon, and Clinical Director of Oral and Maxillofacial Surgery at Glasgow's Southern General Hospital, explained, "Hospitals in Glasgow treat a serious facial injury every six hours, while our nurses help care for around 600 victims every year. The incidence of alcohol-related facial injury in the west of Scotland is higher than in the rest of the UK. Most of the injuries result from inter-personal violence and there is a high incidence of victims returning with similar injuries. My colleagues and I treat some horrific facial injuries, from bruising and swelling to fractures, right up the scale to nerve damage and permanent scarring."

It is hoped the pilot study, which has been funded by the Violence Reduction Unit, will address both drinking and aggressive behaviour in victims with alcohol related facial injury. Three hundred patients of alcohol related facial trauma will take part in the year-long study - the first of its kind in the UK.

Dr Christine Goodall is a clinical lecturer in Oral Surgery at Glasgow University Dental School and is co-ordinating the pilot project. She explained, "Patients will be provided with either an alcohol intervention which we know will help some people reduce their alcohol intake, or a new intervention designed to help patients recognise and avoid potentially violent events in the future. Both of these interventions will be provided by trained nurses, and patients will be followed up for a year afterwards. Clearly the study is just getting off the ground, but if successful, it has the potential to prevent a significant number of recurrent injuries each year and to reduce both the human cost of injury and the actual costs to the health service."

The initiative is being launched during a year-long anti-violence campaign led by the Violence Reduction Unit. 